\title{
Identification of heterotic crosses involving cytoplasmic- genic male sterile lines in pearl millet [Pennisetum glaucum (L.) R. Br.]
}

\author{
P. L. Badhe*, S. M. Thakare ${ }^{1}$, P. N. Rasal ${ }^{1}$ and D. N. Borole ${ }^{2}$ \\ Department of Agricultural Botany, College of Agriculture (M.P.A.U.), DHULE (M.S.) INDIA \\ (Email : pramodbadhe@61gmail.com)
}

\begin{abstract}
Forty eight hybrid combinations were obtained by crossing four male sterile lines (cytoplasm $\mathrm{A}_{1}$ ) with twelve newly developed inbred of a diverse origin. The performance of the hybrids was studied to estimate heterobeltiosis and standard heterosis for grain yield per plant and other related morphonutritional characters. Many of the hybrids exhibited significantly negative heterobeltiosis as well as standard heterosis for days to 50 per cent flowering and maturity indicating possibilities for exploiting heterosis for earliness. The best hybrids were DHLB-15A x K-13/973 and DHLB-16A x K-13/1017, which showed standard heterosis and heterobeltiosis for these traits. Only a few hybrids recorded significant heterobeltiosis and standard heterosis in a desirable direction for plant height and number of productive tillers per plant. Many crosses exhibited heterobeltiosis and standard heterosis for grain yield, ear head length, fodder yield per plant and 1000 grain weight. The crosses DHLB-17A x K13/1005 and DHLB-18A x K-13/1005 exhibited the highest significant standard heterosis and the cross DHLB-18A x K-13/1007 exhibited highest heterobeltiosis for grain yield per plant. None of the cross showed significant heterobeltiosis as well as standard heterosis in desirable direction for $\mathrm{Zn}$ content in grain. The highest standard heterosis and heterobeltiosis for $\mathrm{Fe}$ content in grain were observed in the crosses DHLB-18A x K-13/1017 and DHLB-16A x K-13/1008, respectively. The cross DHLB16A x K-13/1011 showed highest standard heterosis and heterobeltiosis for number of grains per $\mathrm{cm}^{2}$. DHLB-15A x K-13/1009 and DHLB-16A x K-13/1009 exhibited highest and significant standard heterosis for ear head length and 1000 grain weight, respectively.
\end{abstract}

Key Words : Pearl millet, Cytoplasmic-genic male sterility, Heterobeltiosis, Standard heterosis

View Point Article : Badhe, P.L., Thakare, S.M., Rasal, P.N. and Borole, D.N. (2018). Identification of heterotic crosses involving cytoplasmic-genic male sterile lines in pearl millet [Pennisetum glaucum (L.) R. Br.]. Internat. J. agric. Sci., 14 (1) : 133-137, DOI:10.15740/ HAS/IJAS/14.1/133-137.

Article History : Received : 16.06.2017; Revised : 20.11.2017; Accepted : 03.12.2017

\footnotetext{
* Author for correspondence:

${ }^{1}$ College of Agriculture, PUNE (M.S.) INDIA

${ }^{2}$ AICRP on Niger, Zonal Agricultural Research Station, Igatpuri, NASIK (M.S.) INDIA
} 